ulation, Gladding's plan will not get out all the sulphur, but my plan (fluxing with soda) must be adopted.

I have shown that there is not a single point recommended by Gladding, in deviation from my method, which is fit for adoption, and I must conscientiously advise my brother chemists to adhere to the method just as I have laid it down in the "Alkalimakers' Handbook."

In conclusion I would add that I have also tried the method recommended by F. Johnson (Chem. Nerws, I894, 70, 212), omitting to precipitate the iron, but reducing it by sodium hypophosphite to the state of protochloride. Even when working precisely as described by the author, the results were so widely off the truth, that I can make nothing whatever of this plan.

\title{
IMPROVEMENT IN THE MANUFACTURE OF ACETONE.
}

BY E. R. SQU1BB, M.D.

Received January 17,1895 .

THE increasing use of acetone as a chemical solvent, and especially the relation of acetone to the manufacture of chloroform, gives importance to any improvement in its production.

$\mathrm{Up}$ to this time the writer knows of no process of manufacture except by the destructive distillation of acetates at high temperature. The acetates are charged into stills and heated as long as they yield any acetone. Then the acetates being decomposed to waste carbonates are discharged and the stills recharged with fresh acetate, making an interrupted process of repeated charging and discharging and heating and cooling. This process is very old; but two patents have been taken out in this country on some details of the process and apparatus.

The writer proposed to himself to make acetone directly from acetic acid by a continuous process, and has accomplished that object.

In Gmelin's Handbook of Chemistry, Cavendish Society edition, $I 853,8,29 \mathrm{I}$, under the head of decomposition of acetic acid by heat, much work is given where the vapor of acetic acid was

1 Read before the N. Y. Section, January 11 , I895. 
passed through heated tubes, acetone being one of the products; and, on this line of investigation, the writer's work was taken up.

It was not difficult to see that the discrepant results reached by the authorities were due to differing physical conditions, and different degrees of heating, since it was mechanically quite certain that a current of rapor passing through a stationary tube, neated from below, whether empty or filled, could not be heated to the same clegree in all parts of the tube, and therefore could not give the same decomposition in all parts.

The work unclertaken was commenced in very long-necked glass bulbs, held in a horizontal position, so that they might be stationary or be revolved by hand, and these were heated by a bath of Wood's metal-the acid being passed in, and the products coming out through horizontal tubes in the long necks.

Iixperiences with these bulbs led to much better mechanical devices. A small flask was arranged as a still, and from this, by a gas-burner, a constant current of acetic acid vapor could be produced at any desired rate. The rate was regulated by the rate of supply of liquid acid from an elevated graduated supply vessel, the supply going to the still through a glass tube, in which the rate of dropping was seen and controlled by a stop-cock. Then, by varying the acid supply and the heat from the burner, the boiling liquid in the stili could be kept at about a constant level, and with a controllable known rate of vapor supply.

At some distance from this end of this apparatus the condensing apparatus was arranged to receive the distillates. The products of distillation were first received in a flask where most of the watery vapor and undecomposed acid was condensed, but where the temperature continued so high that but a mere trace of acetone was arrested there. From the neck of this flask the remaining gases and vapors passed through a good condenser, which delivered the remainder of the water and undecomposed acid and the acetone into a flask immersed in an ice-bath. Here almost all the condensible vapors were condensed. The gases and uncondensed vapors were taken from the neck of this flask to a small wash-bottle supplied with water, by which the current of gases was washed. Here waste acetone enough was caught to increase the volume of contents to a point at which all went off 
together in the current of gases, and the level remained constant. Next was a wash-bottle containing a strong solution of sodium hydroxide. Through this the residual gases were passed in order that most of the carbon dioxide might be combined. Finally, the gases were passed through another small wash-bottle containing water. At the small exit tube of this bottle the gases were tested for inflammability, and the proportion of methane and carbon monoxide was estimated by the absence or the degree of inflammability. Except at the times of testing, this exit tube was connected to a Sprengel water-pump, and a minus pressure of one to six $\mathrm{cm}$. of mercury was maintained on the entire apparatus. This served to relieve all joints and connections and caused all the leakages to be inward, whilst a mercury-gauge at each end gave due notice of obstruction or irregularities.

These two ends of the apparatus remaining constant, the intervening space was occupied by the varying form of distilling or decomposing apparatus. An earthenware drain-pipe, with movable tile ends served as a furnace. This drain-pipe, supported in a horizontal position, had six holes drilled above and below. Each lower hole was large enough to admit a Bunsen bumer with limited air space around it, while the holes on top, to give exit to the products of the combustion were smaller. The decomposing tubes or stills of wrought iron, with cast iron ends, occupied this drain-pipe furnace, being connected with the vapor supply apparatus at one end and the condenser at the other.

Much preliminary work was necessary in getting the apparatus in good working order, and in following up tangential points, but these are passed over, and only the important work givenand that not always in the order in which it was done, but in an order which brings the results into a more logical sequence more easily understood.

Two strengths of acetic acid were used. First, an acid containing thirty-six per cent. of absolute acid. But as this gave distillates unnecessarily dilute it was generally given up in favor of a sixty per cent. acid, although the reactions were not noticeably different in the use of the two strengths. Hence with two exceptions the results given are from a sixty per cent. acetic acid. 
Reducing the work from the disorderly way in which it was done to a natural order, and rejecting what was not trustworthy, it is best to begin with some repetitions of work already long on record. (See Gmelin's Handbook, and other authorities.)

A tube of wrought iron about thirty-six cm. (fourteen inches) in length by six and five-tenths cm. (two and five-tenths inches) internal diameter, reduced at each end to tubing of about sixtenths cm. (one-fourth inch), was held stationary in the center of the furnace, and connected at one end with the acid vapor supply and at the other with the condensers. This tube could be heated by the gas-burners to any desired degree up to a dull red heat. The trials were made under as nearly the same conditions as practicable, the running time being about three and five-tenths hours, and under close observation. The amount of sixty per cent. acetic acid which could be passed in, in vapor during this time, varied much-generally 250 to $350 \mathrm{cc}$. The quantities used were always reduced to absolute acid $\left(\mathrm{HC}_{2} \mathrm{H}_{3} \mathrm{O}_{2}\right.$ $=59.86$ ), and the results are given in the same acid, but a high degree of accuracy was impracticable, and therefore not aimed at.

( I) With the tube empty and heated nearly to redness at first, and finally to a dull red heat, $290 \mathrm{cc}$. of sixty per cent. acid $=\mathrm{I} 74$ grams absolute acid, was passed in in three and five-tenth.s hours. About I I grams of this acid passed through unchanged, and sixty-three grams were decomposed. That is, about 63.8 per cent. came through unchanged, and 36.2 per cent. were decomposed. In the first receiving flask, kept hot by the vapor, there was no acetone, but only i32 cc. of a fifty-three per cent. acid. In the second flask, in the ice-bath, there was i $5 \mathrm{cc}$. of a thirty-six per cent. acid; and this liquid, roughly estimated by the iodoform test, contained ten to twelve per cent. of acetone. From the final wash-bottle came a strean of inflammable gasprobably methane and carbon monoxide-that would burn almost continuously.

(2) Next, this stationary tube was filled with coarsely granulated pumice-stone, freed from large pieces and from dust, and so tightly packed as to have spring enough to keep the tube full when expanded by heating. Into this, in three and five-tenths 
hours, I 89 grams of absolute acid, in vapor, were passed, and yielded in the first, hot flask $103 \mathrm{cc}$. of fifty-four per cent. acid $=55.62$ grams absolute acid. In the second, ice-bath flask I $_{3} 3$ cc. of 38.4 per cent. acid $=\mathbf{5 2 . 9 7}$ grams of absolute acid, making I08.6 grams out of 189 grams distilled over unclianged, and 80.4 grams decomposed. The contents of this second flask were about 14.5 per cent. acetone. The stream of inflammable gases was estimated as being not less but. rather greater than with the empty tube.

(3) Next, took the pumice from the tube, divided it into two parts, and rejecting one-half, intimately mixed with the other half 500 grams of dry, precipitated barium carbonate. Charged the tube with this mixture, having a little unmixed punice at both ends. Barium carbonate was selected to multiply surface, as being a rather heavy powder that would not shrink nor fuse, nor be likely to decompose.

About $450 \mathrm{cc}$. of sixty per cent. acid $=270$ grams of absolute acid were passed, in vapor, in three and five-tenths hours, into this mixture, heated as before. The distillate in the first, hot flask was eighty-one cc. of acid water of only one and six-tenths per cent. $=$ one and three-tenths grams absolute acid. In the second ice-bath flask was $227 \mathrm{cc}$. sp. gr. about 0.955 , containing one and two-tenths per cent. acid $=$ two and seven-tenths gra:us absolute acid. Of the 270 grams passed in, four grams only distilled over unchanged, while 266 grams were decomposed. The $227 \mathrm{cc}$. of distillate in the second flask contained about 23.3 per cent. of acetone. This proportion gives about twenty per cent. of acetone from the 266 grams of absolute acid used. The stream of inflammable gases was very much greater than in the other experiments, burning with an almost continuous large flame.

The desired splitting of acetic acid to yield acetone requires two molecules of the acid to yield one molecule of acetone, the residuary products being one molecule each of carbon dioxicle and water. That is, I 20 grams of absolute acetic acid should give

$$
\begin{aligned}
& 5^{8} \text { grams of acetone, } \\
& 44 \text { " " carbon dioxide, } \\
& 18 \text { " " water, or }
\end{aligned}
$$


by percentage the acid should give

$$
\begin{aligned}
& 48.33 \text { per cent. acetone, } \\
& 36.67 \text { " } \\
& \text { I } 5.00 \text { carbon dioxide, }
\end{aligned}
$$

When marsh-gas or methane $\left(\mathrm{CH}_{4}\right)$ and carbon monoxide (CO) are formed it is probably largely, if not entirely, through a secondary decomposition of the acetone by a higher heat than that which gives the primary decomposition into acetone, carbon dioxide, and water, and when acetone and methane are produced together, it is rational to suppose that inequalities of heating are the cause. That is, if acetone be produced it indicates that the exact conditions required are present at that time and place. Then it follows that if these exact conditions be extended throughout the whole time and place of reaction the acetone splitting of the acid only can occur, and no methane or other products of other reactions can be produced. The conditions for producing these different reactions are doubtless different degrees of heating, and uniformity of reaction can be expected only from uniformity of heating. And the differences in the degrees of beat required to produce the different reactions here, do not seem to be great.

The physical and mechanical conditions of heating a stationary tube can not possibly yield an equal degree of heating to the contents of such a tube, especially where only a part of such contents is in motion. Even if the whole outside of the tube could be equally heated-as it could not be practically-the contents would be cooler from circumference to center. But in this case, where a current of vapor at about $100^{\circ} \mathrm{C}$. is passed continually, into a tube the outside of which is kept unequally heated to $500^{\circ}$ or $600^{\circ} \mathrm{C}$., and where this current has to find its way at varying speed through varying friction and expansion, only a varying decomposition can be possible, and the conclusion must be that if uniform decomposition is to be reached it must be through uniform conditions.

Equable heating in a stationary tube, under the conditions of this process, being impracticable, it became necessary to devise some better form of still; and a careful consideration of the principles involved, and the especial mechanical difficulties of this 
decomposition, led the writer to a form of rotary still, which, after some alterations and modifications, has proved successful.

A wrought-iron tube about thirty-six $\mathrm{cm}$. (fourteen inches) long by $\mathrm{I} 2.7 \mathrm{~cm}$. (five inches) in diameter, contracted at the ends to central hollow journals of about two $\mathrm{cm}$. (three-fourths inch) external diameter and one and two-tenths cm. (five-tenths inch) bore, free to revolve, was supported in the center of the eighteen cm. (seven inches) drain-pipe furnace and connected at one end with the vapor supply and the other with the condensers by airtight glands or "stuffing-boxes." The ends were provided with charging and discharging openings which could be closed airtight, and the still was revolved slowly by means of a pulley on one end of the hollow shaft. A small stationary tube passed into the still through the revolving shaft to convey the acid vapor to the entrance of the still at one end, and a similar tube gave exit to the products of the decomposition at the other, condenser end. It was necessary to protect this tube from obstruction by dust carried by the current of vapors, and this was done by a cartridge of rolled up, wire cloth, filled with glass wool. This rotary still was driven at the rate of the to six revolutions per minute by a small water-motor, and was found to heat with great equability as it revolved over the burners. Inside of the still, at equal distances apart on the periphery, five L-shaped, longitudinal strips of sheet iron were riveted. These were necessary to prevent the charge from sliding round as the iron became smooth, and they were found to carry the charge round, turn it over, and mix it most effectively at each revolution. Thus, while by the revolutions over the source of heating the shell was heated very uniformly, this continuous moving and turning over of the contents must bring all parts of the charge, solids and vapors alke, in successive contact with the hot surfaces and the cuoler atmosphere of the still, and thus secure a fair degree of equable heating. The still being about one-third filled with the solid charge and slowly rotated, the charge occupies principally, - not the bottom of the still directly over the fire, but the ascending third which has just been over the fire. Then, as the charge is carried up, the superficial cooler portion, too deep to be held by the longitudinal shelves, slides back upon the hot surface below, 
while the portion carried on by the shelves falls back, shelf by shelf, from contact with the hot shell through the atmosphere of vapor, upon the cooler portions below to be mixed and carried up again in a similar order. At the same time the whole atmosphere of the still is filled with dust which becomes very fine, and very largely multiplies the surfaces of contact with the vapor, for decomposition, whilst the vapors pass slowly and uniformly and with a minimum of friction to the exit at the condenser end. If the motion and heating of a charge in this still be compared with those in a stationary still with a horizontal stirrer driven by a vertical shaft, the advantages of the former will be easily understood. The latter moves the charge round over the fire, but has a comparatively slight effect in bringing new portions of the charge successively in contact with the heating surfaces, and it does not tend to prevent horizontal stratification of the charge with consequent irregular heating; and it does not tend to the fullest contact of the vapors with the surfaces of the charge, where the decomposition probably takes place. After the inevitable number of trials and adjustments and breakings down, the following successful experiments are selected from a large number.

(4) As a parallel experiment to (I) with the stationary still, the rotary still was used empty.

A bout $200 \mathrm{cc}$. of thirty-six per cent. acid = seventy-two grams of absolute acid was slowly passed into the heated, rotating, empty still.

The first hot flask of distillate contained thirty-three cc. of acid of 14.6 per cent. $=4.82$ grams absolute acid.

The second ice-bath flask contained $I 42 \mathrm{cc}$. of acid acetone $\mathrm{I} 2.6$ per cent. $=17.89$ grams absolute acid. Then $4.82+17.89=$ 22.7 I grams absolute acid distilled over unchanged. Then seventy-two grams $-22.7 \mathrm{I}=49.29$ grams of acid decomposed. The second distillate gave an estimate of I2. I grams acetone. Then as 49.29 acid: 12.1 acetone: : I00:24.5 per cent. acetone from the acid. The current of inflammable gas was considerable, but less than in ( $I$ ).

(5) The rotary still was charged with about a liter of the same granulated pumice used in (2), and when heated about $295 \mathrm{cc}$. 
of sixty per cent. acid $=177$ grams of absolute acid was passed in, in vapor during three and five-tenths hours.

The first distillate, hot flask, had $108 \mathrm{cc}$. of acid water of four and four-tenths per cent $=4.75$ grams acid.

The second distillate, ice-bath flask, had i $6 \mathrm{cc}$. acid acetone two and four-tenths per cent. acid $=2.78$ grams acid.

Then $4.75+2.78=7.53$ grams acid came over unchanged, out of 177 grams passed in; or, $\mathrm{I} 77-7.53=\mathrm{r} 69.47$ grams decomposed.

The acetone estimated by iodoform was 24.3 per cent. of the acid decomposed.

(6) About 500 grams of precipitated barium carbonate was put into the rotary still on top of the charge of pumice, and when the whole was heated, $380 \mathrm{cc}$. sixty per cent. acid $=\mathbf{2} 88$ grams of absolute acid was passed in, in vapor during three and five-tenths hours.

The first distillate was $108 \mathrm{cc}$. of acid water containing three and nine-tenths grams acid.

The second distillate was $135 \mathrm{cc}$. of acid acetone containing two and seven-tenths grams acid.

228 grams acid - six and six-tenths grams over unchanged $=$ 221.4 grams decomposed.

The estimated acetone was sixteen per cent. of the acid decomposed.

Much inflammable gas throughout the process.

(7) About 456 grams of precipitated barium carbonate put into the cleaned-out rotary still, and when heated 5 io $\mathrm{cc}$. of thirty-six per cent. acid $=\mathrm{I} 83.6$ grams absolute acid was passed in, in four and five-tenths hours. About 24.5 grams of acid came over unchanged, leaving 159.1 grams, decomposed.

The acetone was estimated at 53.7 grams, or about thirty-four per cent. of the decomposed acid.

(8) Charged the rotary still with 1000 grams of dry barium acetate and distilled this acetate as long as it would yield a distillate, and until it was reduced to 770 grams of barium carbonate quite free from acetate. This yielded acetone estimated by iodoform at about sixty per cent of the theoretical quantity.

When the distillation from the acetate had ceased the receivers were changed and $490 \mathrm{cc}$. of sixty per cent. acid $=294$ grams 
of absolute acid were passed into this charge of carbonate in about four and five-tenths hours.

The distillate was received in five fractions.

Ist. $37 \mathrm{cc}$. of acid water containing 15.6 per cent. acid or 5.77 grams.

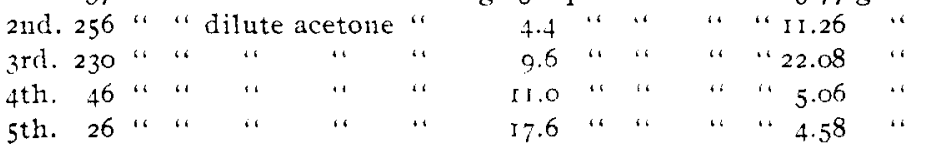

$595 \mathrm{cc}$.

Distilled over undecomposed, 48.75 grams.

294 granı - forty-nine grams $=245$ grams decomposed.

In each of the second and third flasks was about forty cc. of water at the start. Then eighty from 595 gave 5 I $5 \mathrm{cc}$. of total distillate from the $490 \mathrm{cc}$. fed in.

Acetate required from 245 grams acid I 8 grams. Estimated yield seventy-one gram or sixty per cent. of the required yield.

On the following day, without having opened the still, it was reheated and $530 \mathrm{cc}$. of sixty per cent. acid $=318$ grams of absolute acid was passed in, in vapor. From low street pressure in the gas-mains the heat on this day was deficient.

Ist distillate $50 \mathrm{cc}$. acid water containing 19.6 per cent. acid or 9.8 grams.

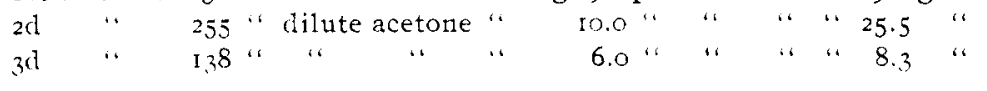

$443 \mathrm{cc}$.

43.6 grams.

318 grams - forty-four grams $=274$ grams acid decomposed.

Acetone required from 274 grams acid 132 grams. Estimated yield ninety-five grams or seventy-two per cent. of the required yield.

On the day following, again without opening the still, in about four hours, passed in $535 \mathrm{cc}$. of sixty percent. acid $=321$ grams of absolute acid.

Ist dis., hot flask, $22 \mathrm{cc}$. acid water containing 7.6 per cent. acid or $1.67 \mathrm{gms}$. 2 c. " ice-bath, 258 " dilute acetone " 4.8 " " " " " 2.38 " 3r " " " 31 " " " " 7.6 " " $" 9.96$ "

$4 I I \mathrm{cc}$. $24.01 \mathrm{gms}$.

32 I grams - twenty-four grams $=297$ grams acid decomposed. 
Acetone required by theory from 296 grams acid I 43 grams. Obtained by estimate about I 3 grams or nearly eighty per cent. of the required yield.

Now, upon cooling and opening the still, samples taken from various parts of the contents were all found to be barium carbonate and free from acetic acid.

During the progress of these distillations from pumice stone, from carbonates, and from the empty stills alike, whenever the supply of acid vapor was cut off the distillation almost instantly ceased, showing that there was then nothing in the still to decompose.

This, then, is the improved, continuous process for the production of acetone directly from acetic acid, which avoids and saves the intermediate steps of forming and decomposing acetates.

The formation of acetates in the still was repeatedly tried with both barium and calcium carbonates, but always failed until the temperature was reduced to about the boiling-point of water, or the condensing-point of watery vapor, and then the acetates formed, cohered and adhered to the ribs and shell of the still, and no longer moved until again decomposed by a higher heat.

Corresponding trials were made with calcium carbonate and with calcium acetate lecomposed to carbonate, with results very similar to those above given, but the barium carbonate seemed to answer best, possibly because it yields a heavier powder that occupies less space and moves better.

When commercial calcium acetate was used, tarry matters obstructed the exit tubes and contaminated the distillates. The portion of these tarry matters that was reduced to charcoal in the still, and there mixed with the carbonate, seemed to be rather beneficial than obstructive. But on the whole the process appeared to do better with carbonates reduced from acetates that were made for the purpose from good materials. As the process seems to be rather a mechanical or physical one of surface contact, it would be reasonable to expect better results from reduced carbonates than from precipitated carbonates. And it is still an open question whether, on the large manufacturing 
scale, with better control of the essentials, heat and motion, pumice or bone black, or some other such substance, will-not be better than the carbonates. Of one thing the writer is quite convinced, and that is that the close regulation of the heating within narrow limits of variation, is far the most important element in the process. Within very narrow limits, too little heat gives undecomposed acid, while too much gives inflammable gases in place of acetone. But on the large scale this element will be under much better control, whilst a proportionately longer still will give the acid vapor farther to go and a prolonged exposure to the limited heating and contact.

There are no patents sought for on this process or apparatus.

The dilute acetone from this process is fairly good and clean, and is colorless except for the action of the free acid contained on the iron tubing. With the free acid the specific gravity by hydrometer varies between 0.93 and 0.97 . No part of the distillate has more than a thin film of oil on the surface too small to be measured, and this oily surface is only in the first flask with the acid water. On further dilution of the ice-bath distillate it is rendered opalescent for a minute or two and then becomes again transparent.

This distillate (undiluted) is a good solvent for many substances, and is probably pure enough for the manufacture of chloroform.

When allowed to stand some days upon caustic lime and then poured off and rectified, it is much improved in character and strength, and is then aclapted to a still larger number of uses, and is perhaps better adapted to the manufacture of chloroform.

The product of this first rectification was then digested with about ten per cent. of dry calcium chloride. This abstracted most of the water and settled in dense solution at the bottom of the bright yellowish acetone. This latter was separated and distilled, and again digested for several days with ten per cent. of fresh calcium chloride, being frequently well shaken. Again twice separated and distilled from fresh portions of calcium chloride, in a capacious flask with a good Hempel tube filled with small glass narbles, and the whole apparatus filled with well-dried air, and distilled directly into specific gravity bottles, such as are described in the Ephemeris, 4, I448-it gave six 
fractions, four of which had the specific gravities at $\frac{1}{1} 5^{\circ} \mathrm{C}$., as follows : First, 0.79662 ; second, 0.79704 ; third, 0.79712 ; sixth, 0.79793 . The irregularities of these differences are doubtless due to differences in rate of boiling, yet they demonstrate conclusively that the first fraction can not be anhydrous.

Authorities differ much as to the specific gravity of acetone. The lowest noticed is, given by W. H. Perkin, Ph.D., F. R. S., in the $J$. Chem. Soc., $1884,45,478$. He gives the specific gravity at $\frac{15^{\circ}}{5}$ as 0.79652 , and at $\frac{25^{\circ}}{2} 5^{\circ}$ as 0.78669 -and says this is lower than that usually observed, but agrees pretty closely with that of Linnemann, who obtained $\frac{1}{1} \frac{5}{5}^{\circ}=0.7975$. Thorpe's number, calculated for this temperature, gave $\frac{1}{1} \frac{5}{5}^{\circ}=0.80244$. Judging from the circumstance that the writer's fractions did not agree, and that therefore there was no constant boiling-point to his distillate, and hence no part anhydrous - his and Perkin's results are both too high.

Notwithstanding this, the writer accepts, for the present at least, his own result as a basis for the following specific gravities of dilutions. His best results as obtained by the use of his above-mentioned specific gravity bottles, and a sensitive thermometer in tenths of a degree, recently compared with a standard, are as follows:

At $4^{\circ} \circ \mathrm{C} .0 .808157$. At $\frac{15^{\circ} 5^{\circ}}{}$ C. 0.796620 . At $\frac{2}{2} 5^{\circ}$ C. 0.786988 .

It was first desirable to know whether dilutions of acetone with water were mere mixtures, or whether as in the case of alcohol there was molecular combination with contraction and elevation of temperature. It was found that when forty cc. of acetone of about ninety per cent. was mixed with forty cc. of water there was a contraction of three and two-tenths cc., and an increase of temperature of $5.6^{\circ} \mathrm{C}$, with an effervescence of gas as in alcohol.

The proportion of ten grams of recently boiled distilled water added to ninety grams of this distillate, mixed by connecting two flasks with the weighed quantities, and passing the liquids back and forth without exposure to external air or loss of vapor, gave the following specific gravities :

Acetone at $\frac{4^{\circ}}{4} \circ \mathrm{C}, 0.8371, \frac{1}{1} \frac{5}{5}^{\circ} \mathrm{C}, 0.8260, \frac{2}{2} 5^{\circ} \circ \mathrm{C}, 0.8168$ for ten per cent. of water, or ninety per cent. acetone. 
This method of dilution by weighing the acetone and water separately in flasks and then connecting the flasks for mixing without loss of vapor or outer air contact was adopted for the basis of the following Acetone Table. The lines of the table that are given in heavy-faced type are given from actual observation, and the remainder by interpolation.

Acetone $=\mathrm{C}_{9} \mathrm{H}_{6} \mathrm{O}$, or dimethyl ketone $=\mathrm{CH}_{3} \mathrm{COCH}_{3}$ is a transparent, colorless, mobile, light, inflammable liquid of an agreeable spirituous or ethereal odor, with a suggestion of mint, and a sharp, biting taste. The suggestion of mint in the odor varies in strength in different samples, and probably does not belong to acetone, but comes from a minute trace of impurity. It boils at $56.3^{\circ} \mathrm{C}$. (Regnault). The specific gravity when very nearly anhydrous is at $\frac{4}{4} \mathrm{C} .0 .808155$, at $\frac{1}{15} \mathrm{C} \cdot 0.796620$, at $\frac{25}{2} \frac{5}{5} \mathrm{C}$. 0.786988 . It mixes in all proportions with alcohol and water, and is a very general solvent. dissolving many substances that are insoluble in alcohol.

\section{ACETONE TABLE.}

The lines of figures in broad-faced type are given from actual observation. The remainder of the table is interpolated.

The Acetone assumed for the basis of the table was not absolutely anhydrous, though probably very nearly so.

In the percentages no account is taken of the weight of the gases liberated on mixing acetone with water.

\begin{tabular}{|c|c|c|c|}
\hline $\begin{array}{l}4^{0} \\
4^{6}\end{array}$ & ${ }_{15^{\circ}}^{15^{\circ}} \mathrm{C}$ & $\begin{array}{l}25^{\circ} \\
25^{4}\end{array} \mathrm{C}$ & $\begin{array}{l}\text { Percent. } \\
\text { are hy } \\
\text { weiglit. }\end{array}$ \\
\hline 0.8082 & 0.7966 & 0.7870 & 100 \\
\hline 0.8 III & 0.7995 & 0.7900 & 99 \\
\hline 0.8139 & 0.8025 & 0.7930 & 98 \\
\hline 0.8168 & 0.8054 & 0.7959 & 97 \\
\hline 0.8197 & 0.8084 & 0.7989 & 96 \\
\hline 0.8226 & 0.8113 & 0.8019 & 95 \\
\hline 0.8255 & $0.81+2$ & 0.8049 & 94 \\
\hline $0.828 t$ & 0.8172 & $0.8 \cdot 79$ & 93 \\
\hline $0.8,313$ & 0.8201 & 0.8109 & 92 \\
\hline 0.8342 & 0.8231 & 0.81 .38 & 91 \\
\hline 0.8371 & 0.8260 & $0.8 \times 68$ & 90 \\
\hline 0.8397 & 0.8288 & 0.8196 & 89 \\
\hline 0.8422 & 0.3315 & $0.82=5$ & 88 \\
\hline 0.8448 & 0.8343 & $0.8 \geq 5.3$ & 87 \\
\hline $0.8+73$ & $0.8,37^{\circ}$ & $0.828 \mathrm{I}$ & 86 \\
\hline 0.8498 & 0.8398 & 0.8309 & 85 \\
\hline
\end{tabular}

\begin{tabular}{|c|c|c|c|}
\hline \multicolumn{3}{|c|}{ SPICLFTC GRATITYAT } & \multirow[b]{2}{*}{$\begin{array}{l}\text { Percent- } \\
\text { age hy } \\
\text { weight. }\end{array}$} \\
\hline $4^{\circ} \quad C$. & $\begin{array}{l}15^{\circ} \\
15^{\circ}\end{array}$ & $\begin{array}{l}25^{\circ} \mathrm{C} . \mathrm{C} . \\
25^{\circ} \mathrm{C} .\end{array}$ & \\
\hline 0.8524 & $0.8+25$ & 0.8338 & 84 \\
\hline 0.8549 & $0.8+5,3$ & 0.8366 & 83 \\
\hline 0.8575 & $0.848 \mathrm{I}$ & 0.8394 & 82 \\
\hline 0.8600 & 0.8508 & 0.8422 & $8 I$ \\
\hline 0.8626 & $0.853^{6}$ & $0.845^{\circ}$ & 80 \\
\hline 0.865 & $0.856 \mathrm{I}$ & 0.8476 & 79 \\
\hline 0.8676 & 0.8587 & 0.8502 & 78 \\
\hline 0.8701 & $0.86 \mathrm{I} 2$ & 0.8528 & 77 \\
\hline 0.8726 & 0.8637 & 0.8554 & 76 \\
\hline $0.875^{2}$ & 0.8663 & 0.8580 & 75 \\
\hline 0.8777 & 0.8688 & 0.8605 & 74 \\
\hline 0.8802 & $0.871+$ & $0.863 I$ & 73 \\
\hline 0.8827 & 0.87 .39 & 0.8657 & 72 \\
\hline $0.8 S_{52}$ & 0.8764 & 0.8683 & 71 \\
\hline 0.8877 & $0.879^{\circ}$ & 0.8709 & 70 \\
\hline 0.8900 & 0.8813 & 0.87 .22 & 69 \\
\hline
\end{tabular}


SPECIFIC GRAVITY AT

$\overbrace{\frac{4}{4}^{\circ} \mathrm{C} . \quad \frac{15^{\circ}}{15^{\circ}} \mathrm{C} . \quad \frac{25^{\circ}}{25^{\circ}} \mathrm{C} \text {. }}^{0.88}$

$\begin{array}{lll}0.8923 & 0.8836 & 0.8756\end{array}$

$0.8946 \quad 0.885^{8}$

0.8969

0.8992

0.9014

0.9037

0.9060

0.9083

0.9106

0.9129

0.915 I

0.9174

0.9197

0.9220

0.9243

0.9266

0.9289

0.9311

0.9334

0.9354

0.9373

0.9392

0.94I I

0.943 I

0.9450
$0.888 \mathrm{I}$

0.8904

0.8927

0.8950

0.8973

0.8996

0.9019

0.904 I

0.9064

0.9087

0.9110

0.9 I 33

0.9156

0.9179

0.9202

0.9224

0.9247

0.9268

0.9289

0.9309

$0.933^{\circ}$

0.9351

0.9371
0.8803
0.8826

$0.885^{\circ}$

0.8874

0.8897

0.8921

0.8944

0.8968

0.8991

0.9015

0.9038

0.9062

0.9086

0.9109

0.9133

0.9156

0.9180

0.9202

0.9223

0.9245

0.9267

0.9288

0.93 โo

\subsection{9}

Percentage by

68

67

66

65

64

63

62

$6 \mathrm{I}$

60

59

58

57

56

55

54

53

52

5 I

50

49

48

47

46

45

44
Specific Grayity at $\overbrace{\frac{4^{\circ}}{4^{\circ}} \text { C. } \quad \frac{15^{\circ}}{15^{\circ}} \text { C. } \quad \frac{25^{\circ}}{25^{\circ}} \text { C. }}^{\begin{array}{c}\text { Percent- } \\ \text { age by } \\ \text { weight. }\end{array}}$

$\begin{array}{llll}0.9469 & 0.9392 & 0.9332 & 43\end{array}$

$\begin{array}{lll}0.9489 & 0.9412 & 0.9353\end{array}$

$\begin{array}{lll}0.9508 & 0.9433 & 0.9375\end{array}$

$\begin{array}{llll}0.9527 & 0.9454 & 0.9397\end{array}$

$\begin{array}{lll}0.9541 & 0.9469 & 0.9413\end{array}$

$\begin{array}{llll}0.9554 & 0.9484 & 0.9430\end{array}$

$\begin{array}{llll}0.9567 & 0.9499 & 0.9446\end{array}$

$\begin{array}{lll}0.9580 & 0.95 I 4 & 0.9462\end{array}$

$\begin{array}{lll}0.9594 & 0.9529 & 0.9479\end{array}$

$\begin{array}{lll}0.9607 & 0.9544 & 0.9495\end{array}$

$\begin{array}{lll}0.9620 & 0.9559 & 0.9512\end{array}$

$\begin{array}{lll}0.9634 & 0.9574 & 0.9528\end{array}$

$\begin{array}{llll}0.9647 & 0.9589 & 0.9545\end{array}$

0.9660

0.9674

0.9687

0.9700

0.9714

0.9727

0.9740

0.9754

0.9767

0.9780

0.9794

0.9604

0.9619

0.9635

0.9650

0.9665

0.9680

0.9795

0.9710

0.9725

0.9740

0.9755

$0.956 \mathrm{I}$

$0.957^{8}$

0.9594

0.96 I I

0.9627

0.9644

0.9660

0.9677

0.9693

0.9709

0.9726

43

42

4 I

40

39

38

37

36

35

34

33

32

31

30

29

28

27
26

25

24

23

22

2 I

20

\section{REPORT OF COMMITTEE ON ATOMIC WEIGHTS, PUB- LISHED DURING I894.'}

By F. W. Clarke.

Received January 2, 1895 .

To the Members of the American Chemical Society:

YOUR committee upon atomic weights respectfully submits the following report, which summarizes the work done in this department of chemistry during 1894 . Although the volume of completed determinations is not large, it is known that several important investigations are in progress, from which valuable results may be expected in the near future. It is in this country that the greatest activity exists, and that the greatest progress is being made at present; and the preparation of these reports is therefore a peculiarly appropriate function of the Society. The data for $\mathrm{I} 894$ are as follows:

The $H: O$ ratio.-An interesting attempt at the indirect measurement of this ratio, which is the base line upon which our sys-

1 Read at the Boston Meeting, December 28, 1894. 